\title{
Development of an in vitro method to determine rumen undigested aNDFom for use in feed evaluation
}

\author{
E. Raffrenato, ${ }^{*} \dagger$ D. A. Ross, ${ }^{*}$ and M. E. Van Amburgh ${ }^{* 1}$ \\ *Department of Animal Science, Cornell University, Ithaca, NY 14853 \\ †Department of Animal Sciences, Stellenbosch University, Stellenbosch, South Africa 7600
}

\begin{abstract}
A portion of the forage cell wall, defined as neutral detergent fiber $(\mathrm{NDF})$, is indigestible to anaerobic microbial digestion in ruminants. This fraction has been characterized by surface area relationships between acid detergent lignin, but recently, data have been published describing the dynamic nature of this relationship. In situ approaches have been described to estimate indigestible NDF, recovering the undigested NDF after long-term fermentations (uNDF). To be applicable to nutritionists and diet formulation, determining uNDF needs to be conducted in a commercial laboratory similar to other routine analyses of forage chemistry. A series of studies were conducted to evaluate an in vitro approach, to describe $\mathrm{uNDF}$, which is repeatable and adaptable for routine feed evaluation. One hundred and two forages of several species were analyzed for NDF, acid detergent lignin, and uNDF. The uNDF was estimated by several approaches involving long-term fermentations and filtration steps to evaluate the length of time necessary to exhaust the digestible NDF and a filtration method necessary to maintain sample integrity by ensuring low sample loss and uniform recovery with residues from long-term in vitro fermentation. To determine $\mathrm{uNDF}$, in vitro fermentations were conducted on 0.50 or $0.75 \mathrm{~g}$ of dry matter samples, in triplicate, at multiple time points up to $504 \mathrm{~h}$ and initially used Gooch crucibles with Celite (Thermo Fisher Scientific, Waltham, MA) as a filtering aid. The final method utilized a $1.5-\mu \mathrm{m}$ pore size glass microfiber filter, which allowed for increased repeatability and improved sample recovery (lowest standard deviation). In this study, in vitro fermentations of 240 $\mathrm{h}$ were adequate to characterize and identify uNDF, which was repeatable among conventional forages provided the samples, after NDF analyses, were filtered through the same glass fiber filter. This approach could
\end{abstract}

Received May 22, 2018.

Accepted July 20, 2018.

${ }^{1}$ Corresponding author: mev1@cornell.edu be adapted by commercial laboratories and would provide opportunities to develop near-infrared reflectance spectroscopy equations and calibrations.

Key words: neutral detergent fiber, digestibility, in vitro, feed evaluation

\section{INTRODUCTION}

Neutral detergent fiber is the most common measure of fiber used for animal feed analysis, but it does not represent a uniform fraction through rumen fermentation (Mertens, 1977). Further, Mertens (2002) published the method that included the option of using $\alpha$-amylase, sodium sulfite, and correcting for ash contamination, abbreviated aNDFom. Further, aNDFom is also characterized by the presence of a fraction that is undigested after exposure to microbial digestion in ruminants (i.e., indigestible aNDFom $=\mathbf{i N D F}$ ) even if total-tract residence time of fiber could be extended to infinite time (Allen and Mertens, 1988; Van Soest, 1994). Thus, by definition, iNDF represents a uniform feed fraction with zero true digestibility according to the Lucas test (Lucas, 1964). As it is impossible to reach infinite time, an approximation of iNDF can be determined utilizing long fermentation time points to determine undigested aNDFom (uNDF). The potentially digestible aNDFom will then result from the difference of aNDFom - uNDF.

A close empirical relationship between silage uNDF and OM digestibility indicates that uNDF is a useful measure for the prediction of the nutritive value of forages (Nousiainen et al., 2003).

Chandler et al. (1980) determined the indigestible fraction of NDF as a function of lignin times 2.4 after fermentation of a modest set of feeds and other materials in methane digesters for up to $120 \mathrm{~d}$ in polyester bags. The 2.4 value was determined on a small number of feeds with a limited range in digestibility and did not represent the variety of forages fed to cattle and agronomic conditions associated with the environment in which many forages are grown. For example, data from Huhtanen et al. (2006b) did not show a general 
relationship between permanganate lignin and uNDF measured after $12 \mathrm{~d}$ in situ fermentation. In the work of Chandler et al. (1980), lignin was measured as $72 \%$ sulfuric acid lignin (i.e., ADL), and that difference could also confound the estimations of Huhtanen et al. (2006b) due to the assumption of linearity between permanganate lignin and ADL and cellulose recoveries. More recently, data from Krizsan et al. (2012) and Krämer et al. (2012) did not show a fixed relationship between lignin and uNDF using in situ long-term fermentations.

Huhtanen et al. (2006b) have suggested that the ultimate extent of NDF digestion might not be reached with an in vitro batch system and the in situ system estimates might be biased due to crucial drawbacks of the traditional nylon bag procedure as discussed by Nousiainen et al. (2004). Nousiainen et al. (2004) determined uNDF by in situ incubations for $12 \mathrm{~d}$ using nylon bags of small pore size $(6-17 \mu \mathrm{m})$, although data from Hvelplund and Weisbjerg (2000) suggested that fermentation to $504 \mathrm{~h}$ was necessary to achieve complete digestion of NDF. The pore size range of 6 to $17 \mu \mathrm{m}$ was determined as the best compromise to minimize particle inflow and outflow, but still allowing adequate microbial activity inside the bags to avoid prolonged NDF digestions (Huhtanen et al., 1998, 2006a). To our knowledge, many research and commercial feed laboratories in the United States use in vitro techniques similar to that described in this paper to determine aNDFom digestibility with samples in direct contact with the rumen fluid and buffer (Goering and Van Soest, 1970; Harvatine and Allen, 2006; Raffrenato et al., 2017), whereas in situ techniques are mostly used in Europe (Krizsan et al., 2012; Krämer et al., 2012).

Several approaches to achieve uNDF have been described (Hvelplund and Weisbjerg, 2000; Weisbjerg et al., 2010; Krizsan et al., 2012; Palmonari et al., 2016) using both in situ and in vitro methods. Some of the uNDF methods have tested different porosity of bags for in situ fermentations to estimate uNDF, but a smaller porosity filter has not been evaluated for long in vitro fermentations. The objectives of this set of studies were (1) to determine the length of fermentation time necessary to identify uNDF using in vitro fermentation; (2) to evaluate a filtration procedure that reduces particle loss and subsequent error of the measurement; and ultimately (3) to develop an in vitro method to measure unavailable aNDFom that is repeatable and has low variability with the capability of being adopted by commercial laboratories as a wet chemical method for routine forage and feed analysis. This paper describes various steps in a sequence over a 2 -yr period, thus some discussion occurs in the Materials and Methods as the procedures evolved.

\section{MATERIALS AND METHODS}

One hundred and two forages of several species [grass forages at various vegetative stages, conventional and brown midrib (bmr) corn silages and alfalfas] were analyzed for aNDFom, ADL, and uNDF. The forages were chosen simply by availability within the laboratory and from other studies with samples of representative forages. All feedstuffs were dried at $60^{\circ} \mathrm{C}$ and ground in a Wiley mill (Arthur H. Thomas, Philadelphia, PA) to pass through a $1-\mathrm{mm}$ screen. The ADF and ADL was performed as described by Van Soest et al. (1991) with the use of a glass microfiber filter (934-AH by Whatman, Whatman Limited, GE Healthcare, Maidstone, UK) and a porosity of $1.5 \mu \mathrm{m}$ inserted in Gooch crucibles (40 to $60 \mu \mathrm{m}$; Raffrenato and Van Amburgh, 2011). The same filter was used for the aNDFom determination, as in Mertens (2002) with amylase, sodium sulfite, and ashing at $550^{\circ} \mathrm{C}$ being applied. Blanks were created by inoculating the flasks with buffer and rumen fluid to correct for any particles introduced into the in vitro system with the rumen fluid. All fermentations were conducted in triplicate and all other analyses were analyzed in duplicate.

The methods described are in chronological order of discovery to arrive at a final approach for assay procedure. Initially, a subset of 12 forages were analyzed at $12,24,48,72,96,144,240$, and $504 \mathrm{~h}$ of fermentation and the contents of the flask were filtered in crucibles with Celite 545 Filter Aid (Thermo Fisher Scientific, Waltham, MA) as a filtering aid (Hvelplund and Weisbjerg, 2000; Mertens, 2002; Van Soest, 2015). These initial samples were selected to have various species represented and to have a wide range of aNDFom and lignin contents. All fermentations were conducted according to Goering and Van Soest (1970) using $0.75 \mathrm{~g}$ of sample DM in 125-mL Erlenmeyer flasks; although the procedure suggests $0.5 \mathrm{~g}$, the sample size was increased to ensure adequate sample remained to effectively weigh the residue. Rumen fluid was always harvested from 2 lactating cows fed a TMR containing corn silage as the primary forage source and 32 to $35 \%$ of total aNDFom, from the Cornell University Research Farm. The rumen fluid was transported to the laboratory in 2 prewarmed 1-L thermoses. Rumen fluid was filtered through 4 layers of cheese cloth and a fabric mesh of $100 \mu \mathrm{m}$ of porosity and glass wool and mixed. Within 30 min of harvest, the rumen fluid was always inoculated into the flasks containing the sample and buffer solution that was reduced under $\mathrm{CO}_{2}$ until the resazurin in the buffer solution turned clear. The proportion of rumen fluid to medium/buffer solution was 10 to $40 \mathrm{~mL}$ as suggested in the original procedure (Goering and Van Soest, 1970). The flasks were swirled at least once per day. 
During the initial evaluations, it was unknown if the bacteria would remain active after a long period in the flask, thus after $120 \mathrm{~h}$ the medium was refreshed, pouring into the flask exactly the same buffer and inoculum mixture as in the beginning, using the same 2 cows and procedure previously described and kept anaerobic at $39^{\circ} \mathrm{C}$ until added into the reduced buffer solution. After several runs, reinoculation was investigated and found not to be necessary, as the bacteria needed to digest the fiber appeared to have adequate viability and activity as long as good anaerobic techniques were used and the $\mathrm{pH}$ was maintained in a range typical of the rumen; the Van Soest buffer was very good at maintaining adequate $\mathrm{pH}$ (data not shown).

After several evaluations, Celite was found to be inadequate as a filtering aid. The recoveries were inconsistent as fermentation progressed and the standard deviation of the residues were very high among time points. The filtration was not efficient and recovered material inappropriately or lost sample in the filtrate. The same small pore size filter used in the lignin analysis was investigated, a Whatman 934-AH glass microfiber filter with a pore size of $1.5 \mu \mathrm{m}$ (Raffrenato and Van Amburgh, 2011), and after several trials, the filter was selected for its ability to retain small particles and filter efficiently under vacuum. The manufacturer of the filter indicates it can be used to retain suspended solids from water samples and small particles of digesta will be suspended in the rumen fluid, so the application to this assay parallels the intended use of the filter. Additional information on particle recovery after long-term fermentations was published by Udén (2006) where it was demonstrated that particles were being lost through typical filtration procedures and recovered in a subsequent centrifugation of the filtrate, indicating the particle size of the undigested material was capable of passing through filter pores $40 \mu \mathrm{m}$ and greater.

Subsequently, fermentations for 12, 24, 48, 72, 96, 144,240 , and $504 \mathrm{~h}$ were conducted to reach the maximum extent of digestion of aNDFom (uNDF), which was then related to that of the forage ADL content. As done initially, the in vitro fermentations were conducted according to Goering and Van Soest (1970) using 0.75 $\mathrm{g}$ of sample DM in 125-mL Erlenmeyer flasks, with and without the use of the glass microfiber filter (Whatman 934-AH) to evaluate potential particle loss from the Gooch crucibles $(40-60 \mu \mathrm{m})$. Preliminary evaluations of various forages were conducted, to estimate when the maximum extent of aNDFom digestion was obtained. The 240-h time period appeared to be adequate because a difference in either digestibility or recovery could not be detected in aNDFom disappearance at longer fermentation times, when using the filter within the crucible. In vitro fermentations were therefore con- ducted for $240 \mathrm{~h}$ for all forages, although it became apparent some forages reached uNDF before $240 \mathrm{~h}$. At the end of the $240 \mathrm{~h}$, samples were analyzed for aNDFom (Mertens, 2002), using the glass microfiber filter (Whatman 934-AH) inserted into the Gooch crucibles as suggested in Raffrenato and Van Amburgh (2011).

In parallel procedures, an in situ fermentation and a fermentation using the Daisy ${ }^{\text {II }}$ Incubator (Daisy ${ }^{\text {II }}$ Incubator; Ankom Technology Corp., Fairport, NY), were conducted for 384, 408, and $432 \mathrm{~h}$ and 288, 312, and $336 \mathrm{~h}$, respectively, with a subset of the samples to assess reproducibility of the UNDF values obtained by the in vitro assay and to compare incubation methods. For both procedures, fermentations were carried out in bags of polyester polyethylene terephthalate (Ankom Technology Corp., Fairport, NY) with $15 \mu \mathrm{m}$ porosity and $8.5 \%$ open area as indicated by Huhtanen et al. (2006a). A sample of $0.75 \mathrm{~g}$ of DM was inserted in each bag and bags were sealed, for both in situ and inDaisy incubations to have no more than $20 \mathrm{mg} \times \mathrm{cm}^{2}$ (Huhtanen et al., 2006a). The same fistulated cows used as the rumen fluid donors for the in vitro procedure were used for the parallel procedures. For the in situ procedure, all bags were sown and glued and inserted in each of the 2 lactating cows. Six bags were mounted on one rubber stopper using plastic ties, and 10 rubber stoppers were gathered in a household washing net with two 900-g weights. The washing nets were connected to the fistula and incubated in the ventral rumen of both cows and the uNDF concentration was reported as the mean of the 2 cows. For the Ankom Daisy, the inoculum and buffer solutions were the same as used in the in vitro procedure and rejuvenation of the media was also performed after $120 \mathrm{~h}$, pouring into each jar exactly the same buffer and inoculum mixture as in the beginning, using the same 2 cows. After the longterm incubations, bags were washed with tap water for $30 \mathrm{~min}$ and dried at $60^{\circ} \mathrm{C}$ for $48 \mathrm{~h}$. The residues were analyzed for aNDFom.

To compare the uNDF residues at 240 and $504 \mathrm{~h}$, the Student's $t$-distribution was used to test the differences between the means (paired comparisons) to detect if the digestible aNDFom was exhausted after 240 h. Further, both Pearson correlation and Lin's concordance correlation coefficients (Lin, 2000) were run between the in vitro reference method and the 2 other fermentations (in situ and in-Daisy) to assess reproducibility of the uNDF values obtained with the in vitro method. Suggestions for interpretation of Lin's concordance correlation coefficient are almost perfect agreement $(>0.99)$, substantial agreement $(>0.95-0.99)$, moderate agreement (0.90-0.95), and poor agreement $(<0.90$; McBride, 2005). The agreement between the reference uNDF (i.e., in vitro) and the in situ and in-Daisy values 
was graphically analyzed using the method described by Bland and Altman (1986). Additionally, the Student's $t$-distribution was used to test the differences between the means (paired comparisons) of the in situ and in-Daisy values, with the values from the in vitro procedure. Values of uNDF obtained with the in situ procedure and the Daisy incubator were also regressed on the in vitro results. The significance of the deviation of the intercept from 0 and the slope from 1 was analyzed by $t$-test. Significance was declared at $P<0.05$.

\section{RESULTS AND DISCUSSION}

\section{Re-inoculation and Filtration Step}

The initial procedure for $\mathrm{uNDF}$ that used Celite in the filtration step resulted in the greatest amount of variation and lack of repeatability (Table 1 and Figure 1A). From the data in Table 1, the recoveries or apparent indigestibility values varied as the fermentation time increased, and of the 12 feeds analyzed, only 2 provided useful data (Timothy grass 1993 and wheat straw 1992). This procedure was repeated several times over several months and the outcome demonstrated a continued lack of repeatability when using the Celite as a filtering agent (data not shown). Also, after several runs, it was determined that error was being introduced through re-inoculation at $120 \mathrm{~h}$ and that practice was stopped. Subsequently digestibility was evaluated without re-inoculation and fermentation and digestion continued effectively under adequate anaerobic techniques and most likely through the use of the Van Soest buffer that has significant reserve buffering capacity. Although the rumen fluid was filtered through cheese cloth, glass wool, and mesh, the data suggested small particles resulting from digestion in the rumen were being introduced into the flask at re-inoculation and the behavior was nonuniform and blank correction did not adequately account for the variation.

A subsequent set of fermentations were conducted using the same forages but with the small pore size glass microfiber filter (Whatman 934-AH) inserted into the Gooch crucibles in place of the Celite. Consistent with the observations of Udén (2006), where centrifugation was necessary to recover the very small particles that escaped filtration, the addition of the $1.5-\mu \mathrm{m}$ filters resulted in a more uniform recovery of particles and a plateau in digestion was also observed (Table 2 and Figure 1B). From this point forward, the glass microfiber filter was used for all filtration steps for all assays to ensure sample integrity and minimize loss. It was recognized that the crucibles used in these studies might have been older with sintered glass filters that were not fully functional, thus requiring the 

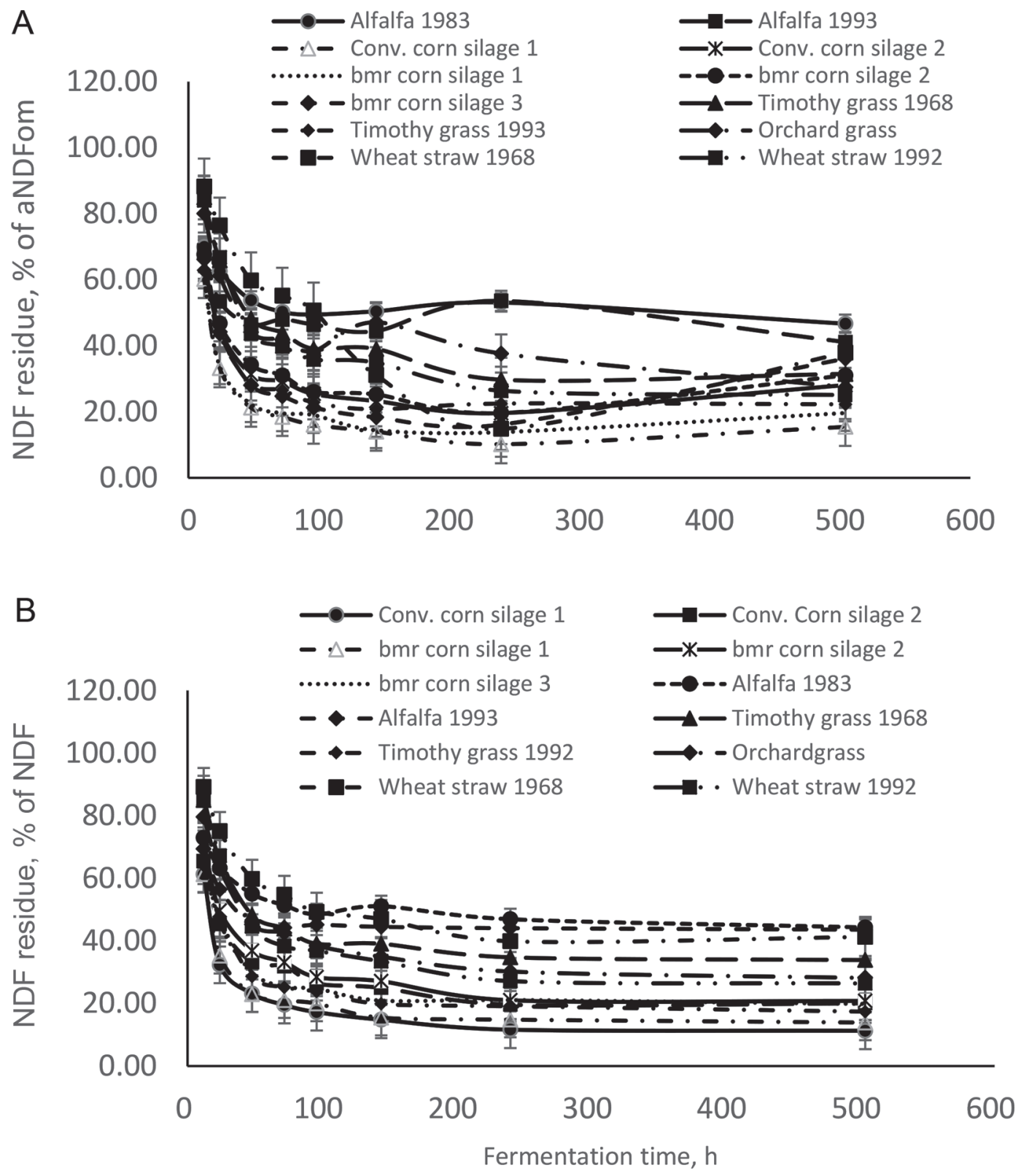

Figure 1. Neutral detergent residue of 12 forages after in vitro fermentation from 12 to $504 \mathrm{~h}$ filtered in Gooch crucibles using Celite (Thermo Fisher Scientific, Waltham, MA) as a filtration aid (A) or using a 1.5- $\mu \mathrm{m}$ pore size glass microfiber filter paper (Whatman 934-AH, Whatman Limited, GE Healthcare, Maidstone, UK) in place of the Celite (B). Conv. = conventional; bmr = brown midrib. aNDFom = method published by Mertens (2002) that includes the option of using $\alpha$-amylase, sodium sulfite, and correcting for ash contamination. Error bars represent $\pm 5 \%$.

use of the filter paper; however, using the filter paper resulted in more uniform values compared with the other approaches, so it appears the smaller pore size was necessary to recover the smaller particle sizes after long-term fermentation (Udén, 2006). In addition, for other systems not utilizing crucibles, the glass filter can be easier to adopt using a filter funnel system.

As a result, the procedures for aNDFom, uNDF, $\mathrm{ADF}$, and ADL resulted in consistently numerically higher values when using the filter than when using the
Gooch crucibles without filter (Table 3). Additionally, fermentation times greater than $240 \mathrm{~h}$ resulted in no differences from the 240 -h values $(P=0.46)$. Values for aNDFom and uNDF (Table 3) and values for ADF and ADL (Table 4) are reported as percent increased recovery compared with not using the filter or using Celite in the crucibles. The use of the filter resulted in higher average uNDF values $(P<0.05)$, among all forage groups, with increased recovery of small particles ranging between $0.0 \%$ and $75.2 \%$, similar to 
Table 3. Percent difference in recovery of neutral detergent fiber $\left(\right.$ aNDFom $^{1}$ ) and undigested aNDFom (uNDF), from the 240-h incubations, when using a glass microfiber filter with $1.5-\mu \mathrm{m}$ porosity compared with no filtering aid in Gooch crucibles for conventional corn silages (CS), brown midrib (bmr) corn silages, grasses, mature and immature grasses, and alfalfas (ranges in parentheses)

\begin{tabular}{lccl}
\hline Group & Samples & aNDFom & \multicolumn{1}{c}{ uNDF } \\
\hline Conventional CS & 30 & $2.3(-0.5$ to 6.4$)$ & $11.9(0.0$ to 40.5$)$ \\
bmr CS & 15 & $2.8(-1.8$ to 3.1$)$ & $11.8(21.2$ to 75.2$)$ \\
Grasses & 13 & $1.8(-0.2$ to 2.4$)$ & $18.2(2.1$ to 48.3$)$ \\
Mature grasses & 11 & $0.4(-0.1$ to 3.0$)$ & $15.2(3.7$ to 46.8$)$ \\
Immature grasses & 15 & $1.1(-1.9$ to 2.1$)$ & $21.3(13.2$ to 56.3$)$ \\
Alfalfa & 18 & $2.7(-1.0$ to 4.2$)$ & $10.1(0.0$ to 35.3$)$ \\
\hline
\end{tabular}

${ }^{1}$ aNDFom $=$ method published by Mertens (2002) that includes the option of using $\alpha$-amylase, sodium sulfite, and correcting for ash contamination.

Udén (2006). Numerically, the highest average increase in recovery was for immature grasses $(21 \%)$ with the largest range in values was for bmr corn silages (11 to $75.2 \%)$. The $\mathrm{ADF}$ and $\mathrm{ADL}$ recoveries among forage groups increased as well $(P<0.05)$, ranging on average between 0.7 and $19.1 \%$ and 3.2 and $38.3 \%$ for ADF and ADL, respectively (Table 4). The difference in recoveries of aNDFom were on average also numerically positive, among all forage groups, and not different than zero $(P=0.27)$.

When evaluated by forage, recoveries increased using the filter paper as the degree of lignification decreased or possibly when stage of harvest was earlier in plant development such as during the vegetative stage such as the immature versus mature grasses as defined by aNDFom content (Table 3). This suggests that as the overall lignin content decreases, or with lower maturity, the degree of cross-linking decreases, and this allows for the formation of smaller particles that have the capacity to flow through the bottom of the sintered

Table 4. Percent difference in recovery of ADF and ADL when using a glass microfiber filter with $1.5-\mu \mathrm{m}$ porosity for ADF and ADL procedure compared with no filtering aid in the Gooch crucibles, for conventional and brown midrib (bmr) corn silages (CS), grasses, mature, and immature grasses and alfalfas (ranges in parentheses) compared with using no filtering aid when filtered through Gooch crucibles $^{1}$

\begin{tabular}{lccc}
\hline Group & Samples & ADF & ADL \\
\hline Conventional CS & 30 & $3.3(-0.5$ to 9.9$)$ & $23.2(2.7$ to 41.0$)$ \\
bmr CS & 15 & $7.0(-1.8$ to 15.1$)$ & $27.5(-1.5$ to 67.2$)$ \\
Mixed grasses & 13 & $0.7(-0.4$ to 5.0$)$ & $10.9(-2.2$ to 29.3$)$ \\
Mature grasses & 11 & $0.8(0.0$ to 4.3$)$ & $8.2(-1.3$ to 23.2$)$ \\
Immature grasses & 15 & $19.1(1.9$ to 11.1$)$ & $38.3(19.25$ to 90.5$)$ \\
Alfalfas & 18 & $2.7(-1.0$ to 11.2$)$ & $3.2(-1.6$ to 10.1$)$ \\
\hline
\end{tabular}

${ }^{1}$ The use of the filter resulted in higher average undigested aNDFom values $(P<0.05)$, among all forage groups, with increased recovery of small particles ranging between 0.0 and $75.2 \%$. aNDFom $=$ method published by Mertens (2002) that includes the option of using $\alpha$-amylase, sodium sulfite, and correcting for ash contamination. 
glass crucible (40 $\mathrm{m}$ porosity) and be lost to recovery. This was demonstrated by Udén (2006) in NDF sample analyses and further demonstrated by Raffrenato and Van Amburgh (2011) in the analyses of ADL. In our previous work (Raffrenato and Van Amburgh, 2011), the increased recovery of ADL among forages averaged $19 \%$ but varied by lignin content, with the lower lignin forages, like bmr corn silages characterized by the greatest differences in recovery, whereas the grass and alfalfa forages demonstrated similar recoveries overall.

\section{Incubation Method}

Consistent with the observations by Boyd and Mertens (2011), the data indicated that $288 \mathrm{~h}$ (12 d) and $384 \mathrm{~h}(16 \mathrm{~d})$ of fermentation were necessary to

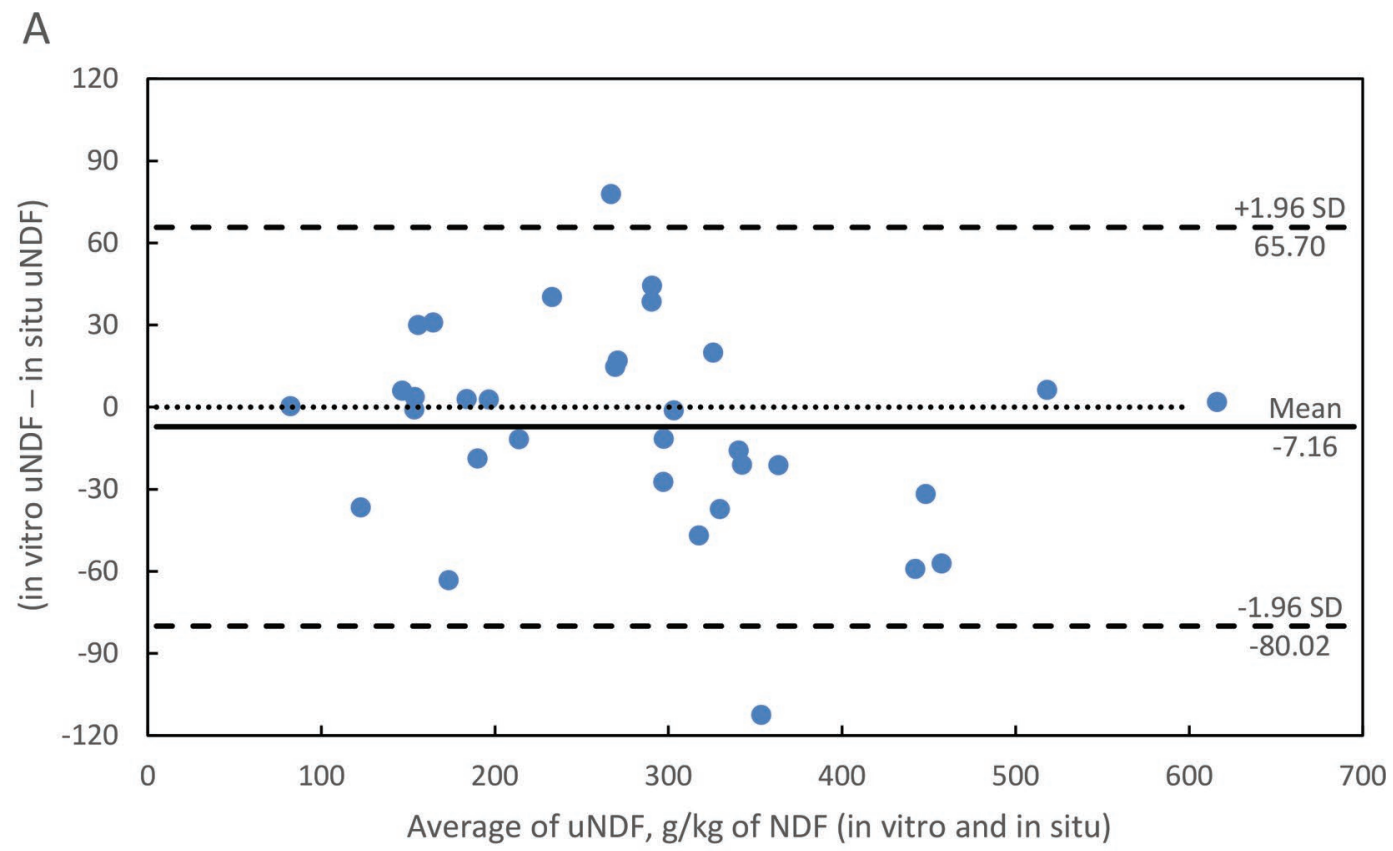

B

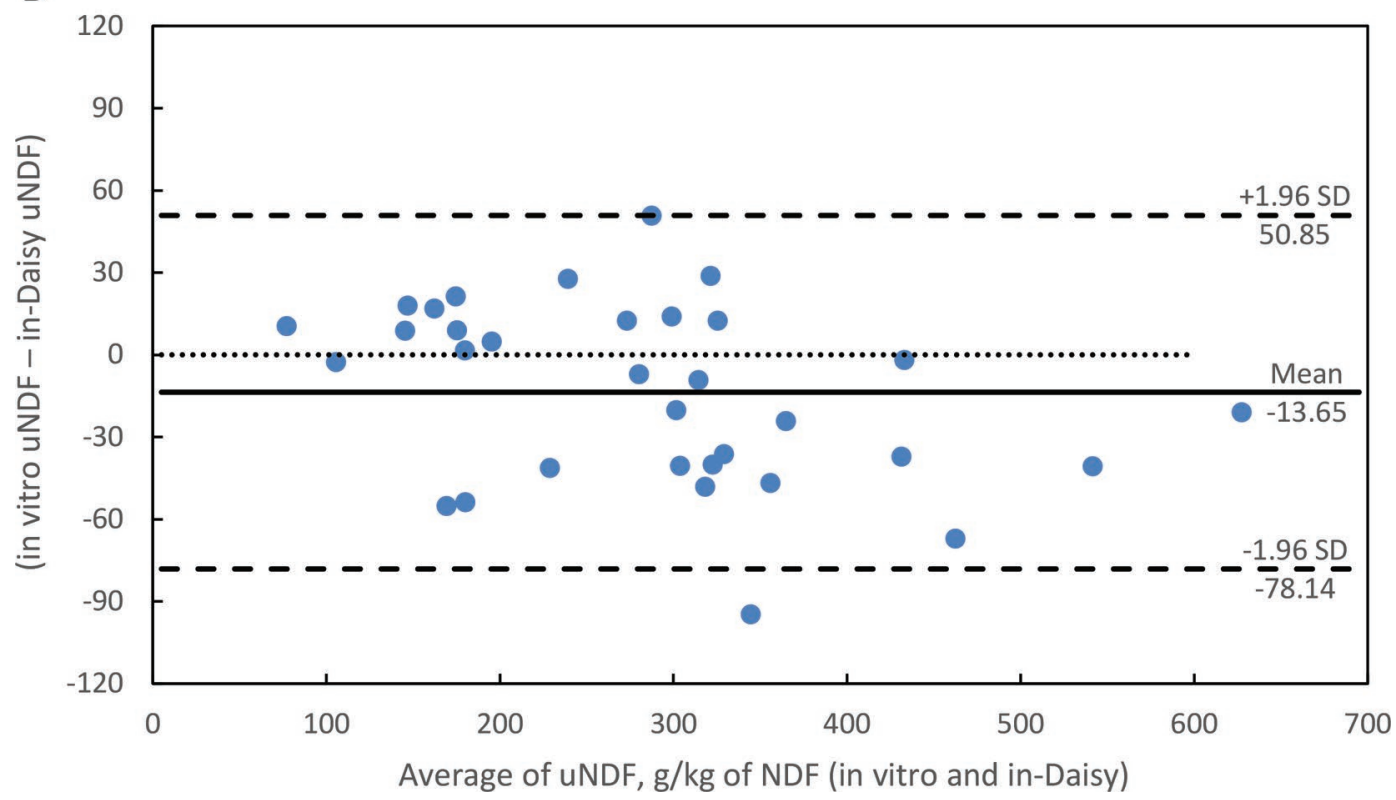

Figure 2. Bland-Altman plots showing agreement between undigested aNDFom (uNDF) estimated using the $240 \mathrm{~h}$ in vitro procedure, used as reference, and the in situ (A) or the in-Daisy procedure (B; Daisy, Ankom Technology Corp., Fairport, NY). aNDFom = method published by Mertens (2002) that includes the option of using $\alpha$-amylase, sodium sulfite, and correcting for ash contamination. Color version available online. 
Table 5. Undigested residues of aNDFom as a percent of the initial aNDFom after in vitro fermentation (240 h), digestion in an Ankom Daisy using bags of polyester polyethylene terephthalate (Ankom Technology Corp., Fairport, NY) with 15- $\mu$ m porosity (288, 312, and 336 h), and digestion in situ $(384,408$, and $432 \mathrm{~h})$ utilizing the same bags as the Daisy with $8.5 \%$ open area ${ }^{1}$

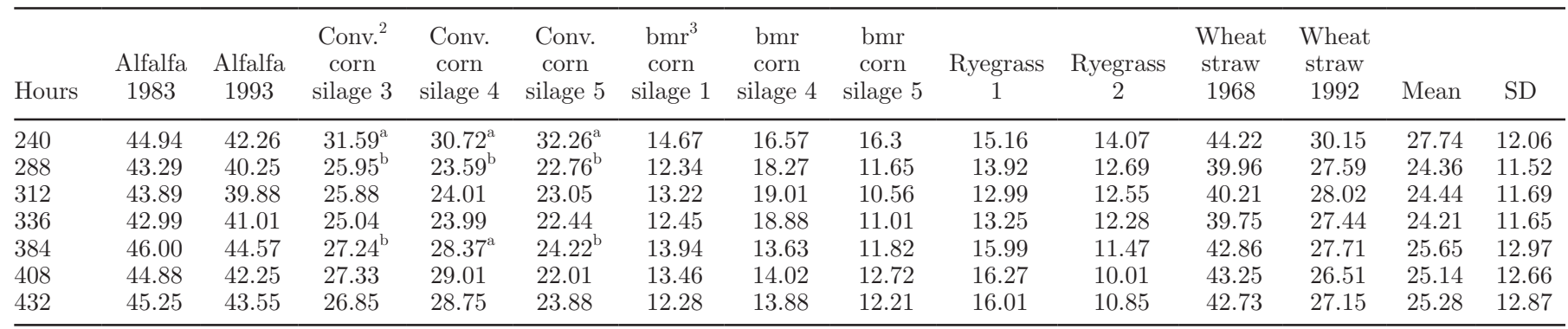

${ }^{\mathrm{a}, \mathrm{b}}$ Different superscripts within a column differ at $P<0.05$.

${ }^{1}$ The overall Student $t$-distribution test of mean differences among 240, 288, and $384 \mathrm{~h}$ undigested aNDFom was $P=0.27$. aNDFom $=$ method published by Mertens (2002) that includes the option of using $\alpha$-amylase, sodium sulfite, and correcting for ash contamination.

${ }^{2}$ Conv. $=$ conventional.

${ }^{3} \mathrm{bmr}=$ brown midrib.

reach the maximum extent of digestion for the Daisy incubator and for the in situ incubation, respectively. Incubation times, needed to reach the maximum extent of aNDFom digestibility in the in situ fermentation, were higher than the in vitro system because the polyester polyethylene terephthalate fabric used minimizes or prevents the flow of particles through the bag and allows only moderate microbial activity within the bags (Huhtanen et al., 1998). However, uNDF values were highly correlated $(P<0.01)$ with Pearson correlation coefficients of 0.87 and 0.89 , between the in vitro and the in situ and the in vitro and the Daisy ${ }^{\mathrm{II}}$ incubator system, respectively. While Pearson coefficients measure the strength of the relationship, both Lin's concordance correlation coefficients and Bland-Altman plots were used to assess agreement. Lin's concordance correlation coefficients were 0.952 (95\% confidence interval $=0.907$ to 0.975 ), between the in vitro and in situ-estimated uNDF, and 0.959 (95\% confidence interval $=0.922$ to 0.978 ) between the in vitro and inDaisy-estimated uNDF, showing substantial agreement between the reference uNDF and the other methods. The agreement between the paired observations is also shown graphically by the Bland-Altman plots in Figure 2. Only 2 observations for the in situ procedure and one for the in-Daisy procedure were outside the \pm 1.96 $\mathrm{SD}$. However, the means of the differences with the reference in vitro procedure were both negative, due to the lower in vitro-estimated uNDF values, when compared with both the in situ and the in-Daisy procedure. Furthermore, pairwise comparisons resulted in no difference between the uNDF values from $240 \mathrm{~h}$ in vitro incubation and the values from both the in situ and in-Daisy $(P>0.05)$ except for the conventional corn silages (conventional corn silages 3,4 , and 5 in Table 5). The differences observed in this comparison

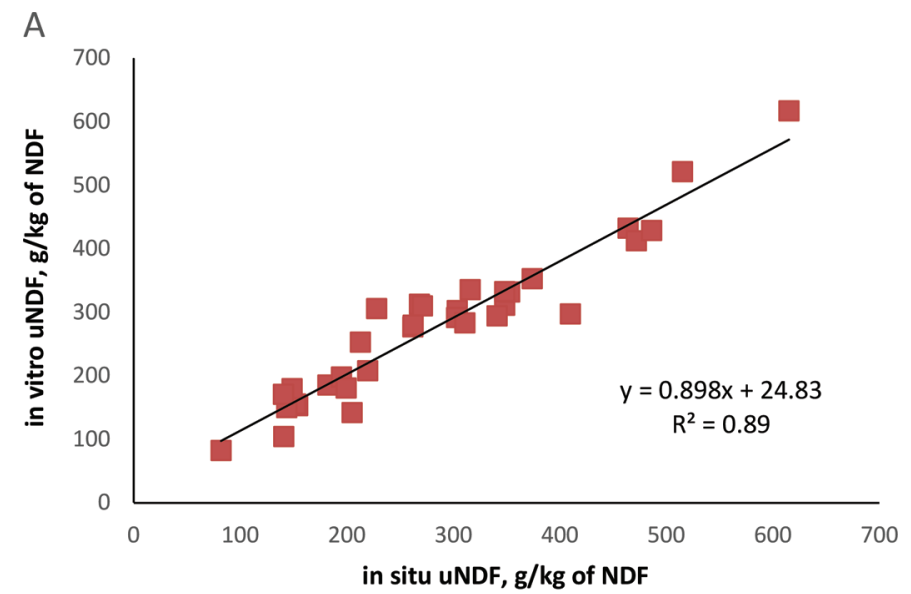

B

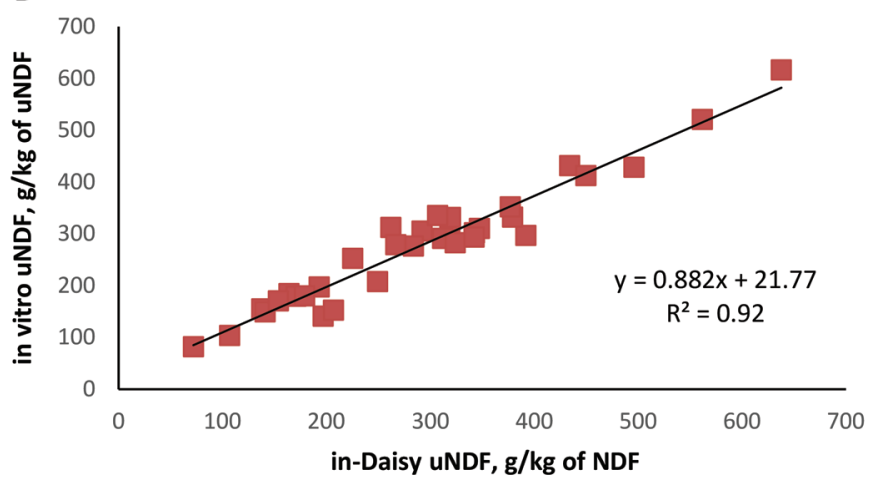

Figure 3. Regression of the undigested aNDFom (uNDF) obtained from the $240 \mathrm{~h}$ in vitro procedure on the UNDF obtained from the 384 $\mathrm{h}$ in situ procedure (A) and on the uNDF obtained from the $288 \mathrm{~h}$ inDaisy (B; Daisy, Ankom Technology Corp., Fairport, NY). aNDFom = method published by Mertens (2002) that includes the option of using $\alpha$-amylase, sodium sulfite, and correcting for ash contamination. Color version available online. 
Table 6. Standard error of the means $(\mathrm{g} / \mathrm{kg})$ and CV $(\%)$ of the undigested aNDFom values per group of forage, by fermentation procedure used

\begin{tabular}{|c|c|c|c|c|c|c|c|}
\hline \multirow[b]{2}{*}{ Forage group } & \multirow[b]{2}{*}{$\mathrm{n}$} & \multicolumn{2}{|c|}{ In vitro } & \multicolumn{2}{|c|}{ In situ } & \multicolumn{2}{|c|}{ In Daisy ${ }^{2}$} \\
\hline & & SEM & $\mathrm{CV}$ & SEM & $\mathrm{CV}$ & SEM & $\mathrm{CV}$ \\
\hline Conv. $^{3}$ corn silage & 5 & 1.511 & 1.68 & 6.137 & 8.32 & 3.132 & 4.69 \\
\hline bmr $^{4}$ corn silage & 5 & 1.054 & 2.25 & 5.232 & 8.11 & 1.573 & 3.75 \\
\hline Mixed grasses & 5 & 2.325 & 2.48 & 2.478 & 5.45 & 2.462 & 3.48 \\
\hline Mature grasses & 5 & 0.624 & 0.84 & 3.734 & 2.93 & 4.656 & 4.26 \\
\hline Immature grasses & 5 & 2.474 & 2.55 & 4.912 & 6.23 & 3.211 & 5.16 \\
\hline Alfalfa forages & 5 & 1.121 & 0.92 & 5.496 & 4.70 & 1.903 & 2.14 \\
\hline
\end{tabular}

${ }^{1}$ aNDFom $=$ method published by Mertens (2002) that includes the option of using $\alpha$-amylase, sodium sulfite, and correcting for ash contamination.

${ }^{2}$ Ankom Technology Corp. (Fairport, NY).

${ }^{2} \mathrm{Conv}=$ conventional.

${ }^{3} \mathrm{bmr}=$ brown midrib.

were not consistent among the 3 corn silages and most likely reflect particle loss out of the bags used in the analysis as the pore size of the bags was larger than that in the filter paper. Overall, the other forages analyzed were not different, suggesting a lack of uniformity in the method if the particle size can vary and the fermentation conditions are not optimized to prevent sample loss.

Regressions of in vitro uNDF values on $\mathrm{uNDF}$ values from both the in situ and the Daisy incubator show positive intercept values, but not statistically different than zero $(P=0.38$; Figure 3$)$. This demonstrates that the in vitro system was able to achieve the extent of digestion within the rumen of a cow, with a lower incubation time required to reach an asymptote (240 vs. 384 h). Furthermore, the Daisy ${ }^{\mathrm{II}}$ incubator can be used to obtain uNDF values using $288 \mathrm{~h}$ residual aNDFom values with the use of the small porosity bags. However, the data showed consistently higher standard errors, and subsequently coefficients of variation, of the uNDF values obtained with both the in situ and in-Daisy systems (Table 6). The use of larger porosity bags, routinely used for the Daisy system (F57; Ankom Technology Corp., Fairport, NY), would likely result in higher variability and risk of loss of precision of the estimated fraction. Again, this suggests the need for smaller porosity bags for both systems to minimize loss of small particles that will overestimate digestion as described by Udén (2006).

\section{Relationship Between ADL and uNDF and Prediction of uNDF}

The CNCPS uses a factor of $2.4 \times$ ADL in aNDFom to describe iNDF of forages (Van Soest et al., 2005). This factor was presumed to be universal among forage species. The use of the glass microfiber filter reduces particle loss when filtering through the crucible for aN-
DFom, uNDF, and ADL. This changes the results of the relationship between ADL, aNDFom, and uNDF (Table 7, Figures 4 and 5). These data demonstrate that the value of 2.4 published by Chandler et al. (1980) cannot be considered valid among all forage groups. Chandler et al. (1980) represents only a population average and because this population has a large range, the recognized invalidity is consistent with previously published data (Palmonari et al., 2016). The only forage close to the range of the data was the alfalfa, which showed the lowest average ratio and the smallest range. The ratio between $\mathrm{uNDF}$ and ADL for alfalfa was numerically the closest to the 2.4 at approximately 2.7 , and this was also observed by Weisbjerg et al. (2010). All other forages averaged approximately 4 , with a range of 2.51 to 6.71 . The ratios of uNDF to ADL were numerically higher for the lower ADL forages (e.g., bmr corn silages

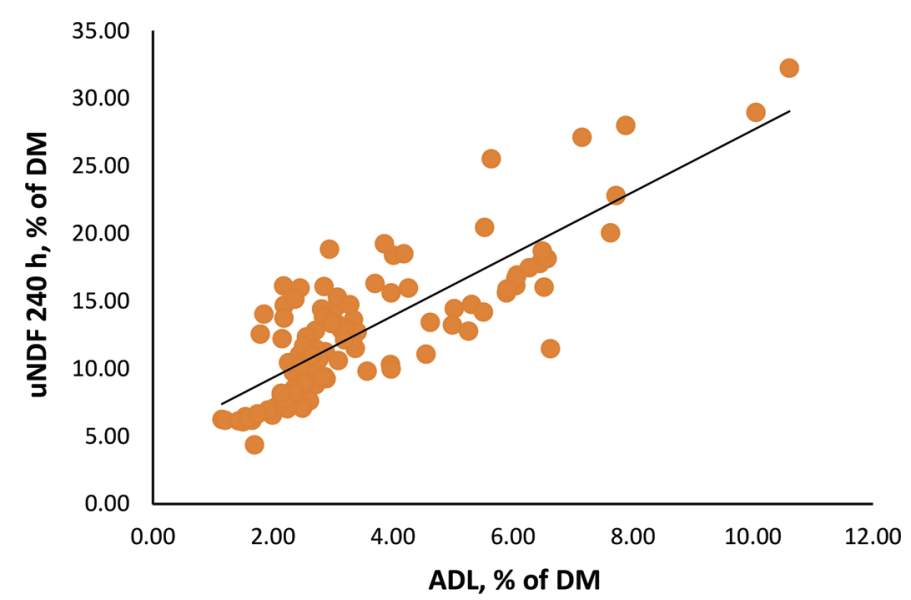

Figure 4. The undigested aNDFom (uNDF; $240 \mathrm{~h}$ ), on a DM basis, regressed on $\mathrm{ADL}$, on a DM basis $\left(\mathrm{y}=2.2889 \mathrm{x}+4.7673, \mathrm{R}^{2}=\right.$ 0.68). aNDFom $=$ method published by Mertens (2002) that includes the option of using $\alpha$-amylase, sodium sulfite, and correcting for ash contamination. Color version available online. 
Table 7. The aNDFom, ADL, undigested aNDFom (uNDF), and calculated ratio of uNDF/ADL values of forages analyzed from the northeastern United States ${ }^{1}$

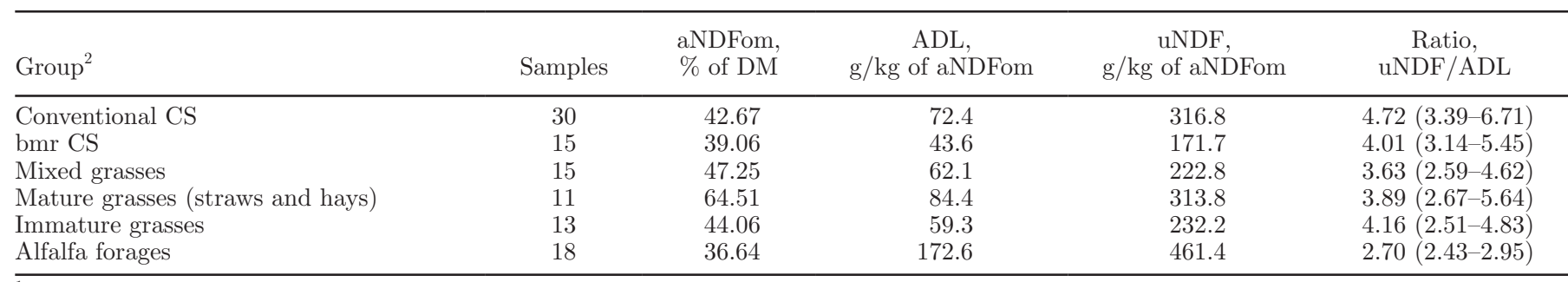

${ }^{1}$ The uNDF was determined after in vitro fermentation for $240 \mathrm{~h}$ and the assays were conducted using a glass microfiber filter with 1.5 - $\mu \mathrm{m}$ porosity. Ranges in the calculated ratio of uNDF/ADL are in parentheses. aNDFom = method published by Mertens (2002) that includes the option of using $\alpha$-amylase, sodium sulfite, and correcting for ash contamination.

${ }^{2} \mathrm{CS}=$ corn silage; bmr $=$ brown midrib.

and immature grasses; Table 5). Thus, the relationship is not static and this could be due to both the filtering method and also inherent biological variation due to cell wall structure. The data presented in this study on a small data set reinforce previous data demonstrating a fix factor of lignin to aNDFom digestibility, as published by Chandler et al. (1980), is not consistent for all forages under all maturity and agronomic conditions (Table 7). In the data of Chandler et al. (1980), the ratio $\mathrm{uNDF} / \mathrm{ADL}$ ranged between 1.5 and 3.0; however, standard filtering procedures were used $(40 \mu \mathrm{m}$ crucibles) and the loss of particles from both ADL and
uNDF might have caused the variation in the ratios for the specific feeds analyzed. Weisbjerg et al. (2010) examined potential laboratory methods for uNDF estimation on grasses and legumes and showed ranges of the ratios between ADL and UNDF of 1.27 to 4.57 and 1.22 to 3.59 for grasses and legumes, respectively, demonstrating the variability in this relationship. Furthermore, Weisbjerg et al. (2010) fermented their samples until $288 \mathrm{~h}$ in situ, using $12 \mu \mathrm{m}$ porosity bags, and ADL values were measured without using a standard procedure, which might not have recovered all of the indigestible materials (Udén, 2006).

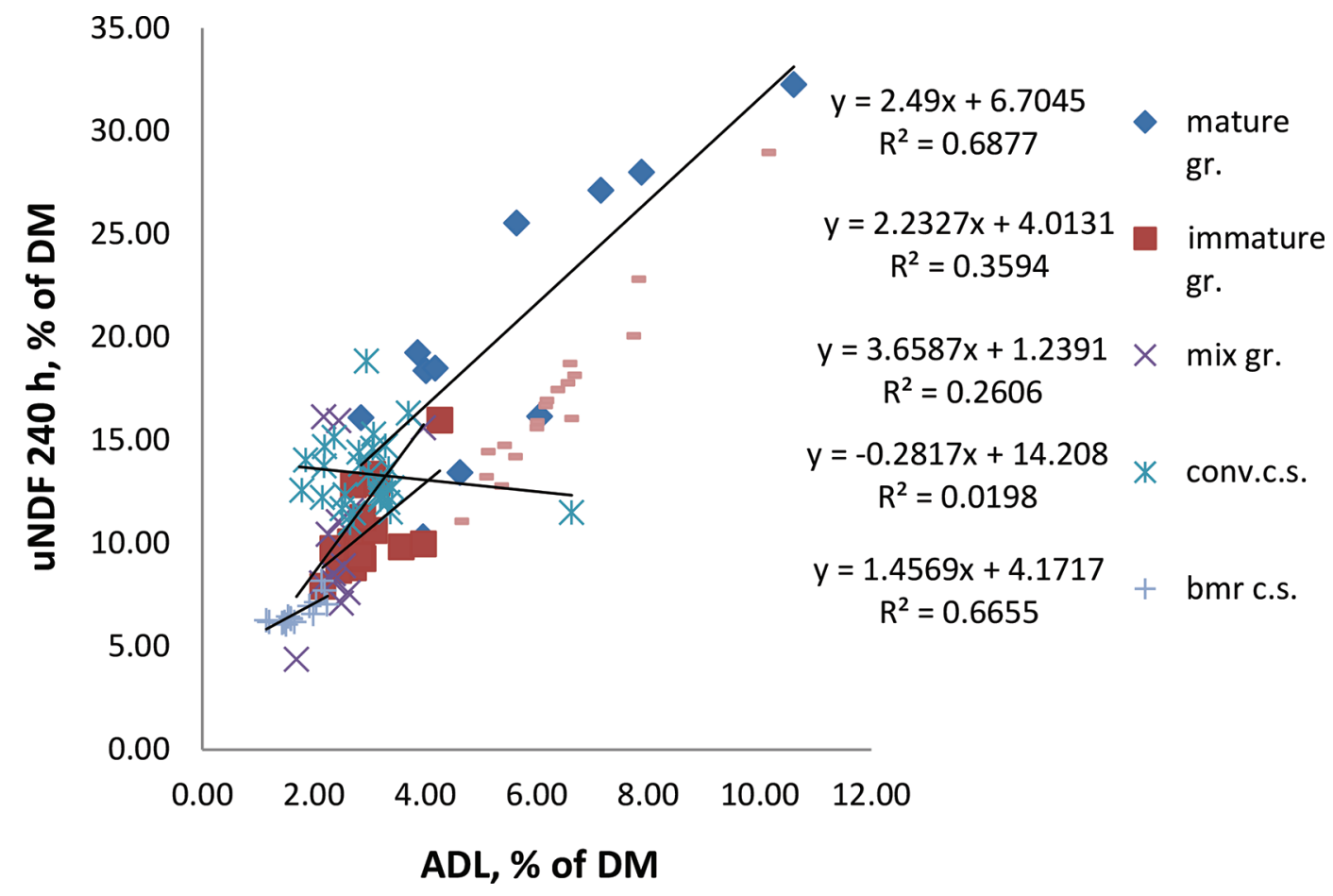

Figure 5. Undigested aNDFom (uNDF; $240 \mathrm{~h}$ ), on a DM basis, regressed on ADL, on a DM basis, grouped by forage families. aNDFom = method published by Mertens (2002) that includes the option of using $\alpha$-amylase, sodium sulfite, and correcting for ash contamination. gr. $=$ grasses; conv. = conventional; c.s. $=$ corn silage; $b m r=$ brown midrib. Color version available online. 
Traxler et al. (1998) had shown that a common equation provides similar estimates of iNDF among forage classes; however, in that study, samples were fermented up to $144 \mathrm{~h}$ and a filtering aid was not used in any procedure. Further, Huhtanen et al. (2006a) observed that the present data do not support a general applicable relationship between permanganate lignin and iNDF measured by $12 \mathrm{~d}$ in situ fermentation, although the overall slope was 2.4. In that case, slopes for individual forages species varied between 2.8 and 5.5, and a general regression equation predicted $\mathrm{uNDF}$ with an unsatisfactory accuracy [coefficient of determination $\left(\mathbf{R}^{2}\right)$ $=0.56$; root mean square error $=27.4 \mathrm{~g} / \mathrm{kg}$ of $\mathrm{DM}]$. By using forage specific relationships, the root mean square error for uNDF was lowered to $14.9 \mathrm{~g} / \mathrm{kg}$ of DM. The data set analyzed here does not support a generally applicable relationship between ADL and uNDF measured by $240 \mathrm{~h}$ in vitro fermentation, although the overall slope was 2.29 (Figure 4) similar to the data of Huhtanen et al. (2006a). Furthermore, the regressions show similar variability around the slope and the separation of the forage groups highlights a strong numerical separation with different slopes according to the forage group (Figure 5). The same regressions on NDF basis resulted in lower $\mathrm{R}^{2}$ and higher variability and are not presented here. From a predictive perspective, the variability in the use of ADL to predict uNDF suggests that it would be better to estimate uNDF directly or use a near-infrared reflectance spectroscopy (NIRS) procedure if a good relationship can be found. In a previous study, Krizsan et al. (2012), in an attempt to associate the NIRS spectra with uNDF obtained by $288 \mathrm{~h}$ in situ fermentations, showed good potential of the technique. However, NIRS can be calibrated for uNDF, and it could potentially improve prediction performance, only by an increased range in reference data. Mentink et al. (2006) reported that biological measurements such as in situ protein fractions and in vitro NDF digestibility are difficult to predict using NIRS because the extent of error in reference methods is high relative to the range of measured values. As such, values predicted by NIRS need to be interpreted with caution. Therefore, the accuracy of a measurement depends on the accuracy of analysis in wet-chemistry. Because of the data compression when using NIRS (i.e., difference in uNDF measured in vitro will be less when using NIRS), accuracy and precision become even more important and therefore we believe that the in vitro procedure here outlined, using improved filtration, should improve the procedure by reducing error in recovery. For routine feed chemistry, the only reason lignin is still analyzed routinely is for the estimation of uNDF either by lignin times 2.4 (Chandler et al., 1980) or the surface area calculation of Weiss et al. (1992), thus any movement toward the actual measurement of uNDF replaces the need to measure ADL.

The data obtained here represent a simple procedure to determine $\mathrm{uNDF}$ and from that a larger range in indigestibility is revealed. This further demonstrates that lignification is a dynamic factor affecting the size of the digestible fraction of aNDFom. For example, a low lignin forage such as bmr corn silage shows a relatively wide range, from 3.14 to approximately 5.4, which indicates that although bmr forages are lower in lignin, the percent of uNDF is relatively high. The use of these higher uNDF values would result in an increase in the estimation of rate of digestion over that currently predicted.

Grasses demonstrated the greatest range and this range was likely due to the inclusion of grasses at many stages of maturity. The very young, early vegetative grasses were in the 2.0 to 3.0 range for the ratio of $\mathrm{uNDF} / \mathrm{ADL}$ but increased to values greater than 5

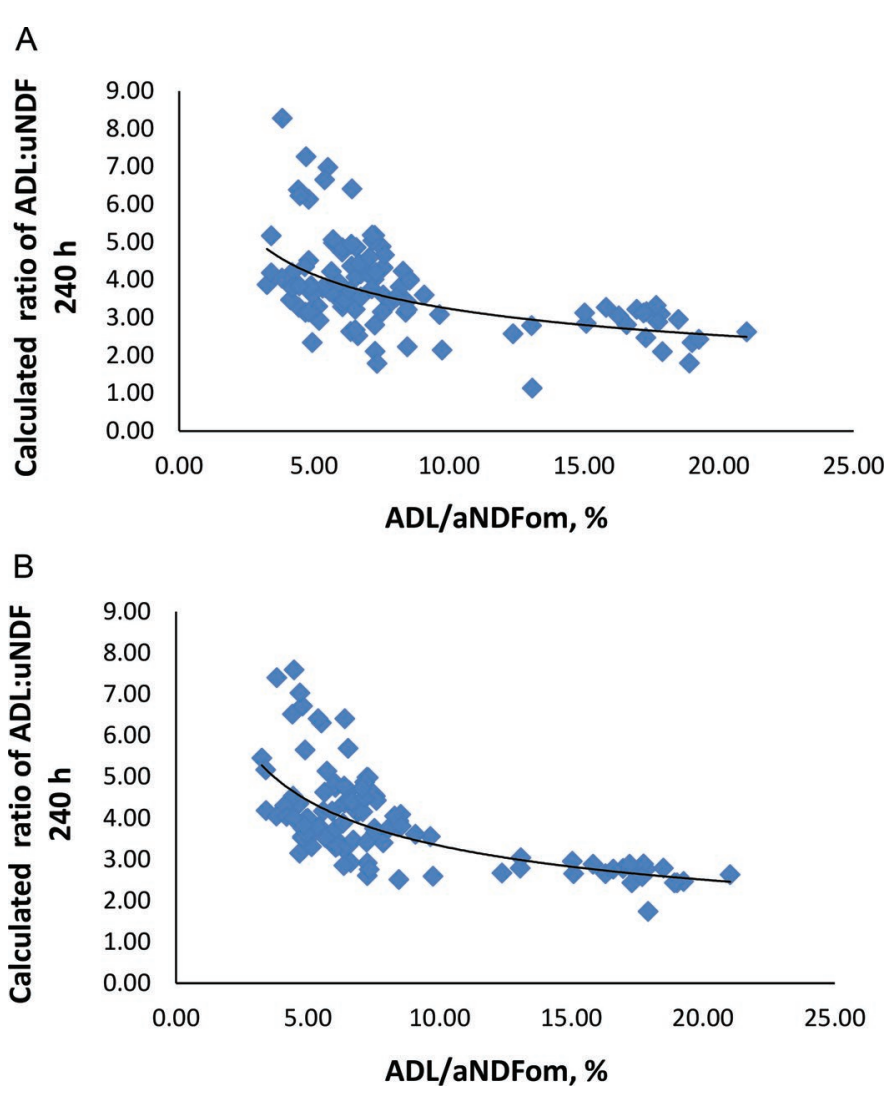

Figure 6. Ratios of undigested aNDFom (uNDF) 240 h/(ADL/ aNDFom) calculated after obtaining uNDF, ADL, and aNDFom without $\left(\mathrm{A}, \mathrm{y}=7.315 \mathrm{x}^{-0.354}, \mathrm{R}^{2}=0.29\right)$ or with $\left(\mathrm{B}, \mathrm{y}=8.5626 \mathrm{x}^{-0.41}, \mathrm{R}^{2}\right.$ $=0.48$ ) a $1.5-\mu \mathrm{m}$ pore size filter paper (Whatman 934-AH, Whatman Limited, GE Healthcare, Maidstone, UK) versus ADL/aNDFom for all forages. aNDFom $=$ method published by Mertens (2002) that includes the option of using $\alpha$-amylase, sodium sulfite, and correcting for ash contamination. Color version available online. 


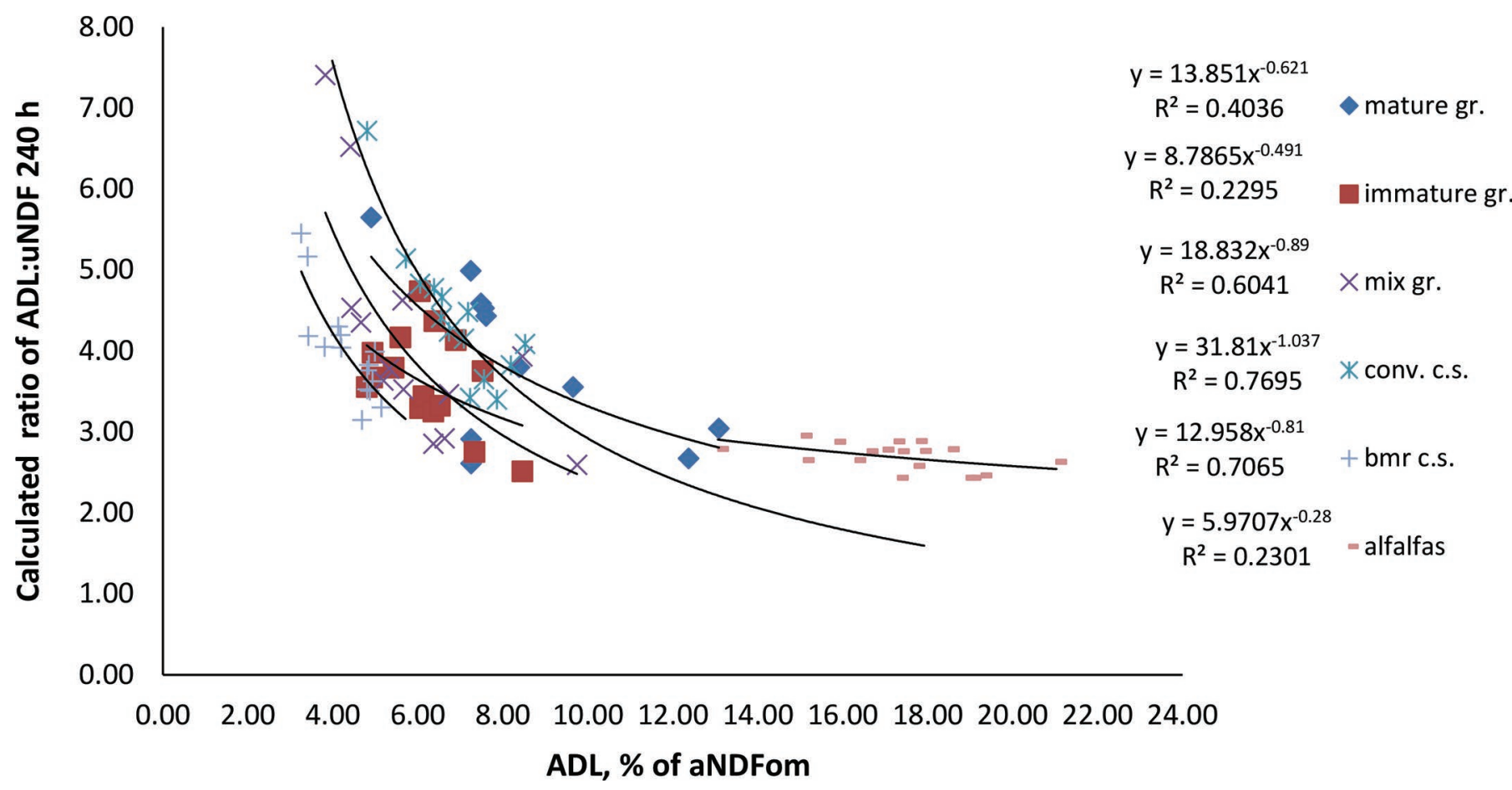

Figure 7. Ratios of undigested aNDFom (uNDF) $240 \mathrm{~h} / \mathrm{ADL}$ calculated after obtaining uNDF, ADL, and aNDFom using a glass microfiber filter (934-AH, Whatman, Whatman Limited, GE Healthcare, Maidstone, UK) versus ADL/aNDFom with forage group-specific equation generated and respective $R^{2}$. aNDFom = method published by Mertens (2002) that includes the option of using $\alpha$-amylase, sodium sulfite, and correcting for ash contamination. gr. $=$ grass; conv. $=$ conventional; c.s. $=$ corn silage; $b m r=$ brown midrib. Color version available online.

for more mature grasses. Thus, 2 overarching factors affect this development of the uNDF pool, the stage of maturity of the plant and the agronomic conditions (e.g., light, heat, water stress, soil type; Struik et al., 1985; Fales, 1986; Deinum and Struik, 1989) that interact with genetics to affect the uNDF. This would help explain why forages, for example corn silage, could be nearly identical in chemical composition, but have widely different digestibilities and result in different cow feeding behavior.

In an attempt to predict uNDF using ADL and aNDFom a series of equations were generated. Among the equations generated, a power function of the type $\mathrm{y}$ $=a x^{b}$, with $y$ representing the ratio and $\mathrm{x}$ being $\mathrm{ADL}$ (on aNDFom basis), resulted in the best fit based on $\mathrm{R}^{2}$. Overall, $\mathrm{R}^{2}$ ranged between 0.10 and 0.43 when not using the filter, and 0.23 and 0.77 when using the filter (Figure 6). Further, regression equations when using the glass microfiber filter are shown in Figure 7. Prediction of the ratio still presents much variability. However, the data clearly show less variability when analyzed within family (Figure 7). Although far beyond the scope of this study the data suggest that genetics, agronomic conditions during development, and physiological stage of the plant at harvest seem to determine the link between the lignin content of the cell wall and how much that affects the extent of digestion, even with the same lignin content (Raffrenato et al., 2017). This appears to be true among forage groups and within groups (Figure 7).

\section{CONCLUSIONS}

These data describe a method for determining uNDF using an in vitro approach that uses a standard and much used fermentation protocol and incorporates a small pore size filter paper to ensure adequate and uniform recovery of the indigestible material. Consistent with previous data, a single value of the ratio uNDF to ADL among and within forages does not properly estimate the size of the potentially digestible aNDFom. Further, this data and laboratory approach should encourage the adoption of the glass microfiber filter to increase recoveries of both ADL and uNDF. Therefore, long-term fermentations should be preferred to correctly quantify the indigestible cell wall and to estimate the size of the digestible aNDFom pool.

\section{ACKNOWLEDGMENTS}

We acknowledge the help and support of Jimmy Robertson (Cornell University, Ithaca, NY) during the con- 
duct of study. His knowledge and humor were greatly appreciated through the evaluation of the fermentation and analysis procedures.

\section{REFERENCES}

Allen, M. S., and D. R. Mertens. 1988. Evaluating constraints on fiber digestion by rumen microbes. J. Nutr. 118:261-270. https://doi .org/10.1093/jn/118.2.261.

Bland, J. M., and D. G. Altman. 1986. Statistical methods for assessing agreement between two methods of clinical measurement. Lancet 1:307-310. https://doi.org/10.1016/S0140-6736(86)90837-8.

Boyd, J., and D. Mertens. 2011. Comparison of alternative methods, sample grinds, and fermentation times for determining indigestible neutral detergent fiber. J. Dairy Sci. 454(Suppl. 94):142.

Chandler, J. A., W. J. Jewell, J. M. Gossett, P. J. Van Soest, and J. B. Robertson. 1980. Predicting methane fermentation biodegradability. Biotechnol. Bioeng. Symp. 10:93-107.

Deinum, B., and P. C. Struik. 1989. Genetic variation in digestibility of forage maize (Zea mays L.) and its estimation by near infrared reflectance spectroscopy (NIRS). An analysis. Euphytica 42:89-98. https://doi.org/10.1007/BF00042619.

Fales, S. 1986. Effects of temperature on fiber concentration, composition, and in vitro digestion kinetics of tall fescue. Agron. J. 78:963966. https://doi.org/10.2134/agronj1986.00021962007800060006x.

Goering, H. K., and P. J. Van Soest. 1970. Forage Fiber Analyses (Apparatus, Reagents, Procedures, and some Applications). Agric. Handbook 379. US Agricultural Research Service, ARS, USDA, Washington, DC.

Harvatine, K., and M. Allen. 2006. Effects of fatty acid supplements on ruminal and total tract nutrient digestion in lactating dairy cows. J. Dairy Sci. 89:1092-1103.

Huhtanen, P., S. Ahvenjärvi, M. R. Weisbjerg, and P. Nørgaard. 2006a. Digestion and passage of fibre in ruminants. Pages 87-135 in Ruminant Physiology: Digestion, Metabolism and Impact of Nutrition on Gene Expression, Immunology and Stress. Wageningen Academic Publ., Wageningen, the Netherlands. https://doi .org/10.3920/978-90-8686-566-6.

Huhtanen, P., J. Nousiainen, and M. Rinne. 2006b. Recent developments in forage evaluation with special reference to practical applications. Agric. Food Sci. 15:293-323. https://doi.org/10.2137/ 145960606779216317.

Huhtanen, P., A. Vanhatalo, and T. Varvikko. 1998. Enzyme activities of rumen particles and feed samples incubated in situ with differing types of cloth. Br. J. Nutr. 79:161-168. https://doi.org/ 10.1079/BJN19980027.

Hvelplund, T., and M. R. Weisbjerg. 2000. In situ techniques for the estimation of protein degradability and postrumen availability. D. I. Givens, E. Owen, R. F. E. Axford, and H. M. Omed, ed. Pages 233-258 in Forage Evaluation in Ruminant Nutrition. CABI Publishing, Wallingford, Oxon, UK. https://doi.org/10.1079/ 9780851993447.0233

Krämer, M., M. R. Weisbjerg, P. Lund, C. Jensen, and M. Pedersen. 2012. Estimation of indigestible NDF in forages and concentrates from cell wall composition. Anim. Feed Sci. Technol. 177:40-51. https://doi.org/10.1016/j.anifeedsci.2012.07.027.

Krizsan, S., L. Nyholm, J. Nousiainen, K. Südekum, and P. Huhtanen. 2012. Comparison of in vitro and in situ methods in evaluation of forage digestibility in ruminants. J. Anim. Sci. 90:3162-3173. https://doi.org/10.2527/jas.2011-4347.

Lin, L. I. 2000. A note on the concordance correlation coefficient Biometrics 56:324-325.

Lucas, H. L. 1964. Stochastic elements in biological models; Their sources and significance. Pages 355-383 in Stochastic Models in Medicine and Biology. J. Gurland, ed. Univ. Wisconsin Press, Madison.
McBride, G. B. 2005. A proposal for strength-of-agreement criteria for Lin's concordance correlation coefficient. Page 6 in National Institute of Water \& Atmospheric Research Ltd., Auckland, New Zealand. Report for Ministry of Health, Hamilton, New Zealand.

Mentink, R. L., P. C. Hoffman, and L. M. Bauman. 2006. Utility of near-infrared reflectance spectroscopy to predict nutrient composition and in vitro digestibility of total mixed rations. J. Dairy Sci. 89:2320-2326.

Mertens, D. R. 1977. Dietary fiber components: Relationship to the rate and extent of ruminal digestion. Fed. Proc. 36:187-192.

Mertens, D. R. 2002. Gravimetric determination of amylase-treated neutral detergent fiber in feeds with refluxing in beakers or crucibles: Collaborative study. J. AOAC Int. 85:1217-1240.

Nousiainen, J., S. Ahvenjärvi, M. Rinne, M. Hellämäki, and P. Huhtanen. 2004. Prediction of indigestible cell wall fraction of grass silage by near infrared reflectance spectroscopy. Anim. Feed Sci. Technol. 115:295-311. https://doi.org/10.1016/j.anifeedsci 2004.03.004.

Nousiainen, J., M. Rinne, M. Hellämäki, and P. Huhtanen. 2003. Prediction of the digestibility of the primary growth of grass silages harvested at different stages of maturity from chemical composition and pepsin-cellulase solubility. Anim. Feed Sci. Technol. 103:97-111. https://doi.org/10.1016/S0377-8401(02)00283-3.

Palmonari, A., A. Gallo, M. Fustini, G. Canestrari, F. Masoero, C. J. Sniffen, and A. Formigoni. 2016. Estimation of the indigestible fiber in different forage types. J. Anim. Sci. 94:248-254. https:// doi.org/10.2527/jas.2015-9649.

Raffrenato, E., R. Fievisohn, K. W. Cotanch, R. J. Grant, L. E. Chase, and M. E. Van Amburgh. 2017. Effect of lignin linkages with other plant cell wall components on in vitro and in vivo neutral detergent fiber digestibility and rate of digestion of grass forages. J. Dairy Sci. 100:8119-8131. https://doi.org/10.3168/jds.2016-12364.

Raffrenato, E., and M. Van Amburgh. 2011. Technical note: Improved methodology for analyses of acid detergent fiber and acid detergent lignin. J. Dairy Sci. 94:3613-3617. https://doi.org/10.3168/ jds.2010-3701.

Struik, P., B. Deinum, and J. Hoefsloot. 1985. Effects of temperature during different stages of development on growth and digestibility of forage maize (Zea mays L.). Neth. J. Agric. Sci. 33:405-420.

Traxler, M. J., D. G. Fox, P. J. Van Soest, A. N. Pell, C. E. Lascano, D. P. Lanna, J. E. Moore, R. P. Lana, M. Vélez, and A. Flores. 1998. Predicting forage indigestible NDF from lignin concentration. J. Anim. Sci. 76:1469-1480.

Udén, P. 2006. Recovery of insoluble fibre fractions by filtration and centrifugation. Anim. Feed Sci. Technol. 129:316-328. https://doi .org/10.1016/j.anifeedsci.2006.01.011.

Van Soest, P. J. 1994. Nutritional Ecology of the Ruminant. Cornell University Press, Ithaca, NY. https://doi.org/10.1016/0301 -6226(95)90011-X

Van Soest, P. J. 2015. The detergent system for analysis of foods and feeds. M. E. Van Amburgh, P. Udén, and P. Robinson, ed. Cornell Publishing, Ithaca, NY.

Van Soest, P. J., J. B. Robertson, and B. A. Lewis. 1991. Methods for dietary fiber, neutral detergent fiber, and nonstarch polysaccharides in relation to animal nutrition. J. Dairy Sci. 74:3583-3597.

Van Soest, P. J., M. E. Van Amburgh, J. B. Robertson, and W. F. Knaus. 2005. Validation of the 2.4 times lignin factor for ultimate extent of NDF digestion, and curve peeling rate of fermentation curves into pools. Pages 139-149 in Proceedings of the Cornell Nutrition Conference, Syracuse, NY.

Weisbjerg, M. R., P. Lund, M. Chrenkova, and M. K. Larsen. 2010. Estimation of indigestible NDF (iNDF) in forages. EAAP Sci. Ser. 127:721-722. https://doi.org/10.1016/j.anifeedsci.2012.07.027.

Weiss, W. P., H. R. Conrad, and N. R. St Pierre. 1992. A theoreticallybased model for predicting total digestible nutrient values of forages and concentrates. Anim. Feed Sci. Technol. 39:95-110. https: //doi.org/10.1016/0377-8401(92)90034-4. 